\title{
EDITORIAL
}

\section{The Scope For OR}

The 1992 OR Society Conference theme was 'World-Class Performance', suggesting that OR in the UK is broadening its horizons significantly. Certainly the excellent plenary sessions would not have been out of place at the British Academy of Management conference held in Bradford the following week. Themes of strategic planning, competitive advantage, quality and change management were very much in evidence. This was all good educational stuff for delegates with a conventional perspective on OR. Even more than at previous conferences, delegates at the Conference had an opportunity to hear about an increasing variety of modern management techniques not usually associated with OR. For example, recent years have seen the appearance of TQM, JIT, OPT, all concerned with improving performance in production - a traditional OR hunting ground - but none related to OR in the eyes of management. In this vein, a recent OR Society newsletter (July 1992), contained a report of an article by Keith Sandrock entitled 'Is OR losing out to manufacturing engineers?' Sandrock argues that manufacturing engineering is increasingly filling the niche that was long thought to be the raison d'etre of OR.

Production control systems like JIT (Just in Time) were motivated by a need to improve performance in the face of increasing competition and a recognition of customer responsiveness as a competitive advantage. This led to a fundamental reappraisal of the whole system of production. With JIT the result was a pull system where products are only manufactured if there is specific demand, in contrast to traditional push systems where finished goods are built for stock. JIT is intended to reduce work-in-progress inventory, simplify shopfloor layouts, improve customer service, improve quality, and reduce costs.

Consideration of the concepts underlying JIT has led to a focus on wider concerns about time-based competition and the entire order management cycle. The idea is to systematically examine all activities in the order management cycle with a view to reducing total time between order and delivery, and improving customer service into the bargain. The approach involves analysing existing organisation processes, understanding how they can be adapted to reduce the cycle time, and changing the organisation following an explicit plan. The potential value of a systematic look at the order management cycle is graphically illustrated in a recent Harvard Business Review article by Shapiro, Rangan and Sviokla. They argue that most companies never view the order management cycle as a whole system: no one, including top management, understands the details of the entire cycle. This can mean for example, that order selection and prioritisation is not properly coordinated to recognise the 'best' orders: where there is a convergence of great customer need, high customer value and good fit with what the company can offer. The fundamental point, say the authors, is that 'the order management cycle is a system, and executives must manage it as a system. The goal, of course, is to fit together the horizontal pieces into a unified, harmonious whole'.

The foregoing illustrates that time-based approaches to production, and order management cycles more generally, are firmly based on the scientific management approach as originally set out by $F W$ Taylor, and the traditional 'OR method'. This method is typically described in simplified form as:

1 describe the problem;

2 formulate a model of the problem;

3 solve the model;

4 test the solution;

5 implement the solution.

Additionally, it is recognised that a large proportion of problems tackled may be resolved before model formulation is complete because the decision situation becomes clarified in a way which makes decision choices obvious. As Chris Chapman (1992) has noted, this is a very basic description of the 'OR method', and one within which a variety of more specified methods can be embedded.

To argue that the emergence of techniques like TQM and JIT represents OR 'losing out' is inappropriate. What has been happening is that production engineers (and others) have been broadening their horizons to addressing management as well as technological problems, usually by appreciating the value of a systems perspective - in effect employing 
the OR method. More and more people without an OR background are recognising the importance of a systematic, systems view of management operations, and a need to understand the fundamental driving forces and interdependencies in these systems. This is a mark of success for engineers and managers. It is not a failure of 'OR' per se.

In the face of all this activity, it is rather optimistic to expect existing operational researchers to play a leading role in every new development. Nevertheless one is inclined to feel disappointed that operational researchers, both 'practitioners' and 'academics', have not been at the forefront of these recent developments in management techniques. Why is this? Historically, work explicitly identified as 'OR' has developed through increasing specialisation in specific kinds of models and specific problem situations. Arguably, operational researchers have failed to recognise just how wide the scope for applying the 'OR method' in management processes really is.

It is tempting to argue that the traditional treatment of OR as a mathematical rather than a management subject in academia has discouraged non-mathematical developments appearing as OR. Instead, recent developments in scientific management techniques have often emerged more conspicuously from management departments and consultancies where mathematical sophistication has not been a prerequisite for research (and concern with practical application is perhaps more emphatic). Outside of academia the positioning of internal OR consultancies in computer services, in management services as a logistics extension of work study has kept OR practitioners busy, if not preoccupied, with a limited range of tactical problems. The restrictive effects of organisational position on project portfolios and growth opportunities are well recognised. It is no accident that commercially aware OR groups seek to represent themselves as (part of) a more general internal consultancy appropriately positioned in the organisational structure.

Of potential concern is any tendency towards specialisation in either model specific or situation specific ways. Of course specialisation is necessary and desirable where there is a need for frequent application of sophisticated techniques, and to the extent that further development of those techniques is sought. However, specialisation can lead to bias in problem diagnosis and solutions applied. The natural tendency of consultants to christen an approach - any approach - with a new name (preferably with a catchy acronym), does not help. Specialisation can lead to myopia and a failure to appreciate general principles and the similarity between the growing number of management techniques and philosophies. Moreover, many OR practitioners do not want to get 'type cast', or 'bogged down in supporting software for particular decision support systems'. 'LP has now escaped into the world of the refinery analyst' was how one speaker at the OR Society Conference put it. One plenary speaker at the Conference argued that specialist OR groups can be vulnerable and may not always be able to contribute in increasingly lean organisational structures. Other speakers in the 'Threats and opportunities for OR groups' stream emphasised the growing commercial awareness of OR groups, and the broadening scope of their work as illustrated by groups called 'Business Consultancy' or 'General Management Consultancy'. A number of conclusions emerged: charging out is becoming more common; there is a need to manage owners' perceptions of OR group consultancy performance by demonstrating added value; and proactive management of the client base is vital. In particular the required skills of the OR worker ought to some extent reflect the skills available in the client base by complementing clients' own skills. One plenary speaker expressed the view that OR departments should be able to respond quickly and flexibly to help clients do more for themselves.

Flexibility and adaptability have become important attributes for would be OR workers, the more so if a period in $O R$ is seen a useful way of training future senior managers.

An increasing number of groups are prepared to expand their repertoires beyond traditional OR techniques. Clearly, OR Society conferences are in tune with this concern for diversification in their choice of streams. What provides a direction for this diversification is a desire to exploit the generic skills of practitioners and the application of a shared, general method of approaching managerial problems.

\section{Stephen Ward}

\section{For the interested reader}

Chapman, C B (1992): My two cents worth on how OR should develop": Journal of the Operational Research Society, Vol 43, pp 647-664.

Goldsbrough, $P$ and Deane, $P$ (1988): 'Time is money' Management Today, September, pp 132-139.

Shapiro, B P, Rangan, V K and Sviokla, J J (1992): 'Staple yourself to an order', Harvard Business Review, July-August, pp 113-122. 